\title{
O OBJETO E LUGAR HÍBRIDO: UMA RELEITURA DE DOM QUIXOTE NA ARTE
}


O OBJETO E O LUGAR HÍBRIDO: UMA RELEITURA DE DOM QUIXOTE NA ARTE

Resumo:

Na perspectiva de entender a intensificação contemporânea das interações das culturas pelos deslocamentos espaciais e midiáticos, este estudo visa contribuir com as pesquisas sobre hibridismo, globalização, arte e comunicação através da "leitura" de Dom Quixote na obra de um artista plástico. Destacam-se, assim, as peculiaridades híbridas do objeto e do lugar como fatores preponderantes da produção cultural.

Palavras chave: Cultura; Globalização; Hibridismo cultural

\title{
THE OBJECT AND THE HYBRID PLACE: A REINTERPRETATION OF DON QUIXOT IN ART
}

\begin{abstract}
:
In a perspective of understand the contemporary intensification of the interaction of cultures by spatial displacements and media, this study aims to contribute with the researches about hybridism, globalization, art and communication through the "reading" of Don Quixote in the work of an artist. Thus highlights the hybrid peculiarities of the object and place as the most important factors of cultural production.
\end{abstract}

Keywords: Culture; Globalization; Cultural hybridism

\section{EL OBJETO Y EL SITIO HIBRIDO: UNA RELECTURA DE DON QUIJOTE EN LA ARTE}

Resumen:

En la perspectiva de entender la intensificación contemporánea de las interacciones de las culturas por los desalojamientos espaciales y mediáticos, este estudio busca contribuir con las investigaciones sobre hibridismo, globalización; arte y comunicación por medio de la "lectura" de don Quijote en la obra de un artista plástico. Destacase, así, las peculiaridades hibridas del objeto y del sitio como factores preponderantes de la producción cultural.

Palabras Clave: Cultura; Globalización; Hibridismo cultural 


\section{INTRODUÇÃO}

Os campos em que atualmente se refletem uma hibridação são vastos dentro da escala cultural. O estudo do hibridismo cultural surge como uma forma de tentar compreender as diversas contradições ou justaposições entre global e local, hegemônico e subalterno, tradição e modernidade. O conceito de cultura é o baluarte para a compreensão desses processos contraditórios em nossa atualidade. Desde suas primeiras concepções, cultura esteve ligada aos processos de criação do ser humano e, de maneira geral, representa o conjunto de características, comportamentos, valores e crenças de uma pessoa ou grupo.

O advento dos meios de comunicação e sua amplificação às massas provocaram novas (re)configurações à cultura. Os estudos realizados por duas escolas que se seguiram a estes acontecimentos, como a Escola de Frankfurt e os Estudos Culturais propuseram-se a compreender este novo fator interligado aos meios de comunicação: circulação intensa de pessoas e bens culturais em escala global e a consequente ampliação das interações entre culturas.

Os processos globalizadores trazem em seu bojo a potencialização da produção, circulação e consumo dos significados sociais (CANCLINI, 1983). Destarte, é com a globalização que o termo hibridismo cultural torna-se recorrente para entender o que resulta dessas interações entre culturas, como se efetiva as representações e no que isso reflete as produções simbólicas dos indivíduos. Por exemplo, muitos artistas da arte contemporânea procuram referências no pretérito para a inspiração e criação de suas obras, mesclam assim características modernas e arcaicas produzindo obras que flutuam entre estes rótulos.

A arte, como um todo, é um dos aspectos da cultura que mais evidenciam características híbridas. Entre as muitas funções da arte, de estilizar o mundo, de transmitir informações, expressar a cultura de determinado povo ou recriar a sociedade, esta atua como um processo comunicacional prioritário do ser humano. Nesse entendimento é que se adentra o objetivo principal deste artigo, o de analisar os reflexos de "O Dom Quixote" nas representações de esculturas. A principal problemática se formulou a partir do questionamento de um clássico literário mundial ter seus expoentes em uma produção artística da região da fronteira oeste do Rio Grande do Sul. Pela dinâmica do "glocalismo" (CANCLINI, 2008) esta análise vem a corroborar com os pensamentos pós-modernos na qual uma globalização não significa homogeneizar e que as hibridações se realizam provocando a inserção das especificidades.

\section{CULTURA E CULTURAS HÍBRIDAS}

"A cultura é uma abstração, o que existe são os indivíduos que criam a cultura, a transmitem e a transformam." (Margaret Mead) 
O conceito subjetivo de cultura, desde meados do século XIX, recebe diversas significações, que abordam desde sua potencialidade como manifestação intrínseca a determinado local, como referência estritamente geográfica, até conceituação de cultura a partir de um valor cognitivo, daquilo que é apreendido pelo indivíduo.

O significado mais primitivo do termo relaciona-se ao "cultivo" da terra, do gado, do campo, em um sentido "agrícola" (THOMPSON, 1995, p. 167) No entanto, a partir do século XVI, passa-se a entender cultura como o "cultivo do saber, do conhecimento", com uma noção generalista de "cultura das letras e das ciências". Essa transição de sentido dá início ao entendimento de cultura como "formação" e "educação" do espírito, apregoado pelo iluminismo francês.

A influência iluminista, em meados do século XVIII, propõe cultura, antes vista como o ato de instruir, como o estado concebido pela instrução. O acúmulo de cognição remete a cultura como o progresso individual do ser humano (CUCHE, 1999, p.21). Os iluministas tinham o vocábulo relacionado à ideia de civilização, de progresso coletivo. Entretanto, outras concepções foram agregadas ao termo.

Os alemães, no entanto, discordam dos iluministas, no sentido de que, teoricamente, esta ideia de civilização dos franceses tinha sentido superficial, o qual englobava aspectos de aparência, hábitos e boas maneiras. Na concepção alemã, "kultur" refere-se a um caráter considerado maior, mais importante, ligado às produções artísticas de seu povo, expressões morais e intelectuais.

A similitude nestes casos é o fato de o conceito ter sido usado em favor ou razão das circunstâncias contextuais históricas. Para os lluministas era interessante englobar em uma única palavra o conjunto de todas as características que consideravam relevantes em sua crença. Já para os franceses, em uma releitura do conceito iluminista, cultura aludia ao povo e à universalização. E por sua vez os alemães moldaram-na de forma a constituir uma "arma" de mobilização e unificação popular.

Mas foi com os estudos introduzidos pelos antropólogos Edward Tylor $(1832$ - 1917) e Franz Boas (1858 - 1942) que esses contrapontos em relação à definição e conceituação de cultura serviram de base para o surgimento do conceito científico de cultura. Tylor dava o "conhecimento, as crenças, a arte, a moral, o direito, os costumes e as outras capacidades ou hábitos adquiridos pelo homem" (TYLOR apud CUCHE, 1995, p.35) como resultado não de uma hereditariedade ou "herança" biológica, mas sim de uma vivência, experiências em sociedade. Essa visão retirou parcialmente o caráter geográfico do conceito e permitiu o estudo da cultura como conceito neutro e universal. Ou seja, sendo desenvolvida ou primitiva, sempre haveria uma cultura universal, seja qual for a sociedade.

Já Franz Boas considerava a cultura como específica de cada sociedade: a soma de tradições, saberes e costumes que demonstravam os fatores pecu- 
liares de cada grupo. A partir dessa perspectiva surgem as primeiras correntes teóricas para pensar o estudo da "cultura". Neste sentido, ele contribui para as pesquisas sobre os fenômenos culturais, inserindo conceitos como "traço cultural" e "área cultural". Foi um dos primeiros teóricos a tratar as diferenças como não sendo raciais, mas sim culturais (CUCHE, 1999, p. 40).

A inserção e crescimento dos meios de comunicação de massa, no entanto, refletem-se na forma com que os teóricos abordam o tema. A escola de Frankfurt, por exemplo, criada em 1923, insere o conceito de cultura intrínseco aos modelos econômicos vigentes na época, quando estavam em ascensão o capitalismo e a industrialização. Surgem dos expoentes pesquisadores como Max Horkheimer, Theodor Adorno e Jurgen Habermas os termos "cultura de massa" e "consumo cultural massivo" (CUCHE, 1999; WOLF, 1999).

Para a Escola de Frankfurt, a chamada "indústria cultural", termo criado por Adorno para substituir "cultura de massa", padronizava e racionalizava as produções simbólicas, o que tirava a capacidade de pensamento próprio do indivíduo. Nesta concepção, viam a cultura como um produto a ser vendido. Ou seja, propunham novas conceituações para a obra de arte "na era da técnica", da produção em larga escala. Estes teóricos consideravam os meios de comunicação de massa como os principais influenciadores da indústria cultural. Eles definiram "cultura" como uma mercadoria de lazer e entretenimento, diversão e distração (ADORNO, 1971).

A abordagem Frankfurtiana à indústria cultural, consequentemente à cultura, serve para explanar as múltiplas facetas que a cultura incorpora ao seu contexto social. A partir de 1964 os "Estudos Culturais" propuseram uma nova leitura sobre cultura. Esta corrente desponta a partir de um projeto sobre subculturas operárias dentro do Departamento da Universidade de Birmingham na Inglaterra. Tem por base a diversidade metodológica para uma pesquisa mais flexível, alcançando uma argumentação amplificada do sentido de cultura:

A cultura é entendida tanto como uma forma de vida - compreendendo idéias, atitudes, linguagens, práticas, instituições e estruturas de poder - quanto toda uma gama de práticas culturais: formas, textos, cânones, arquitetura, mercadorias produzidas em massa, e assim por diante (CARY, TREICHIER \& GROSSBERG, 1992, p. 15).

Para os Estudos Culturais, o próprio modo de viver e representar o cotidiano de um indivíduo caracteriza-se como cultura. Portanto, a perspectiva dos Estudos Culturais permite adentrar na "cultura" em um sentido mais atual, na qual a dinâmica da globalização e do fluxo moderno de pessoas, valores, sentidos, proporcionam uma maior interação entre as diferentes culturas (CANCLINI, 2008). Em suma, os Estudos Culturais e suas derivações teóricas foi uma das primeiras correntes a observar o papel dos meios de comunicação em reformular o conceito de cultura, sociedade e consumo. 
O hibridismo cultural, dentro do contexto dos Estudos Culturais, nasce da ideia de que o dinamismo social efetiva o termo cultura como mescla e mistura, devido à associação provocada pelos contatos culturais. A tendência à hibridação dentro das questões global-local, e dos "pares ordenados de conflito": culto-popular, tradicional-moderno, hegemônico-subalterno; denominam a terminologia "culturas híbridas", que são aquelas dispostas a compreender os resultados desta interculturalidade (CANCLINI, 2008). De maneira geral, hibridização despontava como perspectiva de compreensão dos processos de interações resultantes das mesclas, como sugere Canclini (2008):

A construção lingüística (Barkhtin; Bhabha) e a social (Friedman; Hall; Papastergiads) do conceito de hibridação serviu para sair dos discursos biológicos e essencialistas da identidade, da autenticidade e da pureza cultural. Contribuem, de outro lado, para identificar e explicar múltiplas alianças fecundadas: por exemplo o imaginário pré-colombiano com o novo-hispânico dos colonizadores e depois com o das indústrias culturais (Bernard; Gruzinski), a estética popular com a dos turistas (DeGrandis), as culturas étnicas nacionais com a das metrópoles (Bhabha) e com as instituições globais (CANCLINI, 2008, p. XXI).

Essa "colonização", no contexto de hibridização, manifesta-se claramente nas análises propostas por Douglas Kellner em “A cultura da mídia” (2002), no qual ele infere a ideia de que a arte, representada principalmente por cinema, música e pintura, servia como parâmetro de imposição das chamadas "culturas dominantes". Por exemplo, os filmes produzidos nos Estados Unidos, eram comercializados em escala mundial, e tornavam-se possível que modos de vida, hábitos culturais e tradições antes regionalistas e restritas geograficamente, fossem difundidos em países como o Brasil, um dos principais consumidores do cinema americano.

Mas o momento de maior expansão das pesquisas, agora sob essa temática de "hibridação", ocorreu na década final do século XX. Ganhava impulso e força dentro dos contextos da descolonização à própria globalização recente, vindo a abranger muitos segmentos da cultura, de hibridações gastronômicas de diferentes países até a arte dos gibis, uma fusão do gráfico com a linguagem urbana literária (BURKE, 2003).

Neste sentido, hibridismo cultural permite a análise de um contexto contemporânea das culturas e suas peculiaridades frente a globalização. No âmbito da América Latina este tema é destacado, pois sua colonização desde o começo foi marcada por uma interposição da cultura européia, sendo que traços originários permaneceram e hoje se relacionam com as propostas de modernização. Essa temática, apresentada por Nestor Garcia-Canclini em "Culturas Híbridas", é utilizada como premissa para a reflexão proposta neste estudo. 


\section{CULTURAS HÍBRIDAS NA ATUALIDADE: OS APECTOS DA ARTE}

$\mathrm{Na}$ etapa moderna, tanto as propostas de um difusionismo tecnológico quanto as de uma "americanização" dos hábitos de consumo aparentemente denotam um sentido de unificação da cultura. Este cenário forma-se em meio à multiplicidade de localidades que, mesmo pela tentativa da homogeneização, se destacam pela relação de coexistência. No contraponto entre global-local outras antíteses imergem no cenário global. Para Canclini (2008) o arcaico e o moderno interagem entre si representados por tradições que perduram entre a aceleração de uma proposta de modernidade. Entre o culto e o popular quase não se tem uma diferença considerável da observada em outras épocas. Toma-se como exemplo as manifestações culturais como o Tango na Argentina, que ao surgir, era tido como dança imprópria para a alta sociedade, sendo praticado principalmente por prostitutas em bordeis e pubs. Na atualidade, essa prática cultural é dada como onipresente no país e é praticada ainda em outros países da América latina. Ou seja, as especificidades se justapõem em uma hibridação constante, posto que o sentido "hibridismo cultural" vem para designar e procurar explicar estas interações. Não acontece um rompimento entre estes sentidos, mas um circuito em que se "entra e sai" (CANCLINI, 2008, p. 17).

Neste sentido, Canclini (2008) ressalta que o objeto de estudo são as relações estruturais que causam o híbrido, ou seja, os motivos que o geram, assim reconstruindo as "relações de sentido" na mistura. O hibridismo procura analisar não a "hibridez" em si, mas sim os processos. Abarca um conceito de movimentação e provisório.

Assim é possível reconhecer o que contem de desgarre e o que não chega a fundir-se. Uma teoria não ingênua da hibridação é inseparável de uma consciência crítica de seus limites, do que não se deixa, ou não quer ou não pode ser híbrido (CANCLINI, 2008, p. XXVI).

Nestes aspectos, portanto, como afirma Canclini (2008), hibridismo cultural serve para pensar em sua generalidade, atualmente tudo se cria e se reconverte. As lógicas do moderno, do arcaico, do global e do local já têm suas fronteiras rompidas, pois o processo de hibridação coloca no mesmo patamar as oposições, fazendo-as coexistir.

O fator que mais ocasiona culturas híbridas é esta dinâmica contemporânea em que a mídia, a economia e as artes proporcionam a interação de diferentes contextos culturais. Destes contatos, seja pelas migrações, pelas viagens ou pela mediação dos dispositivos midiáticos, ocorrem as produções híbridas. Artefatos, estruturas ou lugares que representem estes processos são facilmente encontrados em nossa sociedade. Segundo as idéias de Canclini (2008), em um presente de fluidez, marcado pela complexidade das relações, 
a diversidade dos contextos interculturais em que são inseridos os artistas nos remetem a uma versatilidade híbrida de interpretações dos objetos criados.

Nesse sentido, a arte funciona como o operador discursivo que demonstra as experiências sociais, sendo de fundamental importância não apenas analisar o material, mas também as condições extra artísticas, o circuito que promove a criação e elaboração, as diferentes ligações estabelecidas. Como afirma Canclini apud Becker (2008, p. 41) "o estudo das estruturas internas do mundo artístico, revela conexões centrífugas com a sociedade", a qual "na modernidade os mundos da arte são múltiplos, não se separam taxativamente entre si, nem do restante da vida social". A partir das estruturas pré-definidas e pré-concebidas, insere-se a fragmentação, a colagem, o acúmulo de experiências que torna possível a hibridação.

\section{O DOM QUIXOTE}

Um dos maiores expoentes literários de todos os tempos, Dom Quixote de La Mancha é uma produção bibliográfica datada de 1605, do espanhol Miguel de Cervantes. No contexto europeu da época, os chamados romances de cavalaria alcançavam grande êxito entre a população e a obra funcionou como uma própria sátira ao contexto da época. Infere-se aí, que as produções simbólicas humanas sempre exprimem, além das características individuais do artista, o contexto social em que está inserido, relatando a cultura da época (WILLIANS, 1992).

O personagem principal da narrativa, acolhido pela leitura e fantasiado pelas histórias contidas nos livros de romances, vê-se tomado pela fantasia, e auto denomina-se cavaleiro e "Dom". As inserções sociológicas presentes na leitura, do colapso entre viver o real e o irreal são temáticas abordadas ao decorrer da história do fidalgo Dom Quixote. O personagem torna-se exemplo de virtudes que em muito identificam a quem lê e isso denota o êxito da produção ter perdurado ao decorrer dos séculos. A longa distância, em termos históricos, com a contemporaneidade não é empecilho para esta obra refletir-se de maneiras diversas, sob reproduções tanto nas mídias, nas artes, e na própria música.

No Brasil, principalmente pelas adaptações de programas de TVs, a história foi sendo difundida entre jovens, adolescentes e adultos. A inserção das mídias, neste sentido, de reposicionar um produto cultural é, por assim dizer, uma característica dos sentidos de troca cultural. A interculturalidade é a coexistência de culturas, os quais são processos precursores de um hibridismo cultural. Assim, o hibridismo serve para "designar as misturas interculturais propriamente modernas, entre outras, aquelas geradas pelas integrações dos Estados nacionais, os populismos políticos e as indústrias culturais" (CANCLINI, 2003, p. XXVII). 
Canclini (2007) sugere que as mudanças globalizadoras alteram a maneira de conceber a cultura. Esta não se percebe apenas como o objeto de estudo voltado as culturas locais - tradições, língua e costumes -, mas dentro de uma perspectiva abrangente devido ao plano atual de intercâmbios, trocas, migrações, fluxo de pessoas, objetos e mensagens (globalização). O sentido local de nascimento agora não é suficiente para definir os pertencimentos e passa a funcionar como um meio pelo qual a relação entre os grupos se efetua (CANCLINI, 2007).

Os pertencimentos, atribuídos ao local de surgimento do livro Dom Quixote não ficam restritos à Espanha (seu país de origem), pois do contato propiciado por meios de divulgação e principalmente da acelerada crescente das mídias, o livro torna-se mundial. Caracteriza-se ainda assim, como uma expressão do seu contexto cultural da época. Porém, a partir do contato com outras culturas - que o faz despertencente de seu país de origem - a obra, por meio da criatividade individual e desta troca, conjectura como resultados produções híbridas dentro dos contextos mais diversos, além Espanha.

Assim, principiam-se a salientar-se as localidades e suas especificidades em produções híbridas. Nesta análise, o hibridismo cultural como resultado da interculturalidade do livro europeu em uma cidade brasileira, pode ser demonstrado através das obras de arte do artista plástico Lupe Barbosa.

\section{O OBJETO E O LUGAR HÍBRIDO: RETRATAÇÃO DE “O DOM QUIXOTE"}

Natural de Uruguaiana - RS, Lupe de Souza Barbosa é um artista plástico que tem na sua especificidade a fabricação de esculturas. Sua história artística data desde sua adolescência, na década de 1980, ano em que por meio de uma viagem à capital do estado do Paraná, teve contato com a escola de Belas Artes de Curitiba. Neste local principiou por aprender e desenvolver suas primeiras técnicas artísticas, como entalhe em madeira, óleo sobre tela, objetos em gesso, etc. Após pouco tempo, Lupe voltou a morar em sua cidade de origem, Uruguaiana. Já adulto, decidiu participar da escola de artes da cidade (Escola Livre de Belas Artes - ELBA). Deste contato, Lupe começa a desenvolver novas técnicas e descobre uma forma peculiar de criar arte: usando a solda elétrica. Desde então o ferro, a sucata e a lata sobrepostos na solda tem-se transformado em esculturas diversas com seu trabalho.

Ao partir do princípio de que o objeto híbrido é aquele originário de duas estruturas separadas, pode-se entender a obra material de Lupe Barbosa como um artefato híbrido. Seu trabalho consiste na utilização de técnicas de soldador para converter materiais já descartados em obras de arte. Este processo de criação traz a reciclagem em seu aspecto. Com duas práticas humanas distintas: soldar e reciclar, o artista as funde e gera suas esculturas. Isto demonstra uma característica da hibridação ao mesclar estes aspectos. Volta-se assim às 
noções de cultura anteriormente destacadas, agora se enquadrando às praticas simbólicas:

ela é também a parte do ambiente resultante da transformação da natureza pelo homem, com seu trabalho. (...) A cultura é, por excelência, o domínio do artificial e do convencional (VILA NOVA, 2004, p.54).

Desta forma, Lupe ao operar a transformação de objetos por meio de seu trabalho, cria novos significados, sendo esta também uma manifestação específica de cultura criada por meio da individualidade humana. Assim, o cotidiano social é refletido nas artes.

Neste sentido, o objeto efetiva-se como um artefato cultural híbrido. Por tratar-se de um trabalho também autossustentável, muitos deles foram construídos com o recolhimento de materiais nas ruas, nas construções civis e nas visitas a sucatarias da cidade e doação de amigos. A técnica e formas adquiridas, surpreendente pelo material, atestam uma estética contemporânea, mas fundamentalmente abarcam a primeira definição de hibridismo de Canclini (2008, p. XIX):

Entendo por hibridação processos sócio-culturais nos quais estruturas ou práticas discretas, que existiam de forma separada, se combinam para gerar novas estruturas, objetos e práticas.

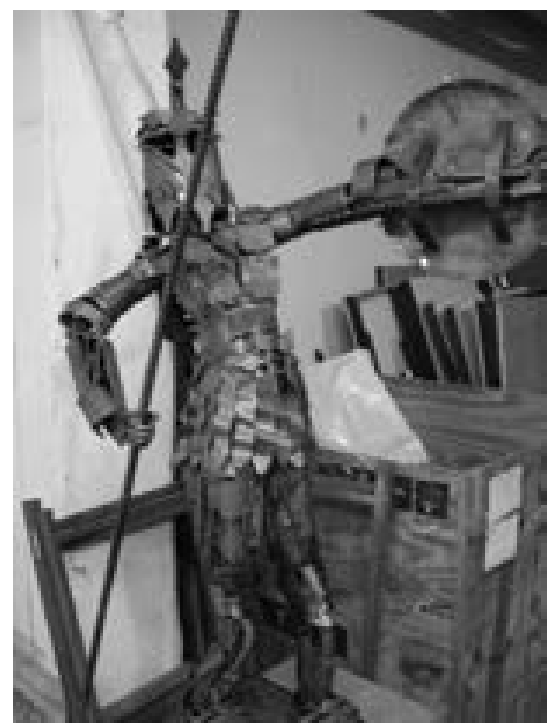

Figura 01: A arte como objeto híbrido Fonte: SOARES (2011)

Esta primeira contextualização da história do artista permite também constatar que devido a um processo migratório (tendência global) o artista interagiu em diferentes localidades e esta experiência se reflete em 
uma nova forma de produção, no caso a criação da arte. O processo híbrido, neste sentido, acontece dos processos migratórios.

Como a hibridação funde estruturas ou práticas sociais discretas para gerar novas estruturas e novas práticas? Às vezes isso ocorre de modo não planejado ou é resultado imprevisto de processos migratórios, turísticos e de intercâmbio econômico ou comunicacional (CANCLINI, 2008, p. XXII). [Grifo nosso]

Mas foi da influência midiática que o artista descobriu sua peculiaridade em esculpir Dom Quixotes. Relata o escultor que seu primeiro contato com a literatura de Cervantes não foi com o livro, mas sim através do programa televisivo, denominado "Sítio do pica-pau amarelo". O global surge para ele por intermédio midiático, pois o artista não se deslocou de sua localidade para conhecer o personagem ou, até mesmo, o lugar de origem da obra (contexto). A comunicação entra como uma mediação desta interação. Isto corrobora a tendência que a interculturalidade é acelerada pelas mídias, proposta por Canclini (2003, p. 73), pois

Os meios audiovisuais, o correio eletrônico e as redes familiares ou de amigos tornaram incessantes os contatos intercontinentais que no passado levavam semanas ou meses. Não é a mesma coisa o desembarque de um avião e uma aterrisagem, nem a viagem física e a navegação eletrônica. A interculturalidade hoje se produz mais por meio de comunicações midiáticas que por movimentos migratórios.

As condições de interação entre culturas e as misturas interculturais acontecem impulsionadas pelos meios de comunicação. Assim a arte não se cria de maneira isolada, mas cada vez mais conectada (pelos dispositivos midiáticos) e interagida (pelo contato de diferentes culturas).

O hibridismo cultural desterritorializa as culturas e as insere em um novo ambiente, atua como um processo de ressimbolização como o caso da obra Dom Quixote. Remete-se aí a um processo em que elementos díspares geram novos objetos culturais na tentativa de traduzir a cultura de uma região em outra.

Ademais, o fato do livro ser um produto cultural mundial, que é representado em uma região interiorana do Rio Grande do Sul, tem em sua especificidade a saliência da produção cultural artística que transita entre o global e o local. Como é recorrente do hibridismo cultural, não se pode afirmar qual pode ser seu aspecto mais saliente, pois os dois segmentos se mesclam, coexistindo entre si.

Hoje, significativamente, a obra encontra-se na Rodoviária de Uru- 
guaiana, local onde o trânsito de pessoas se faz intenso, a remeter aos aspectos de troca que os circuitos globalizadores proporcionam, bem como ao próprio personagem Dom Quixote: cavaleiro errante que se faz andante pelo mundo a criar do seu imaginário um próprio modo de ver e viver no mundo.

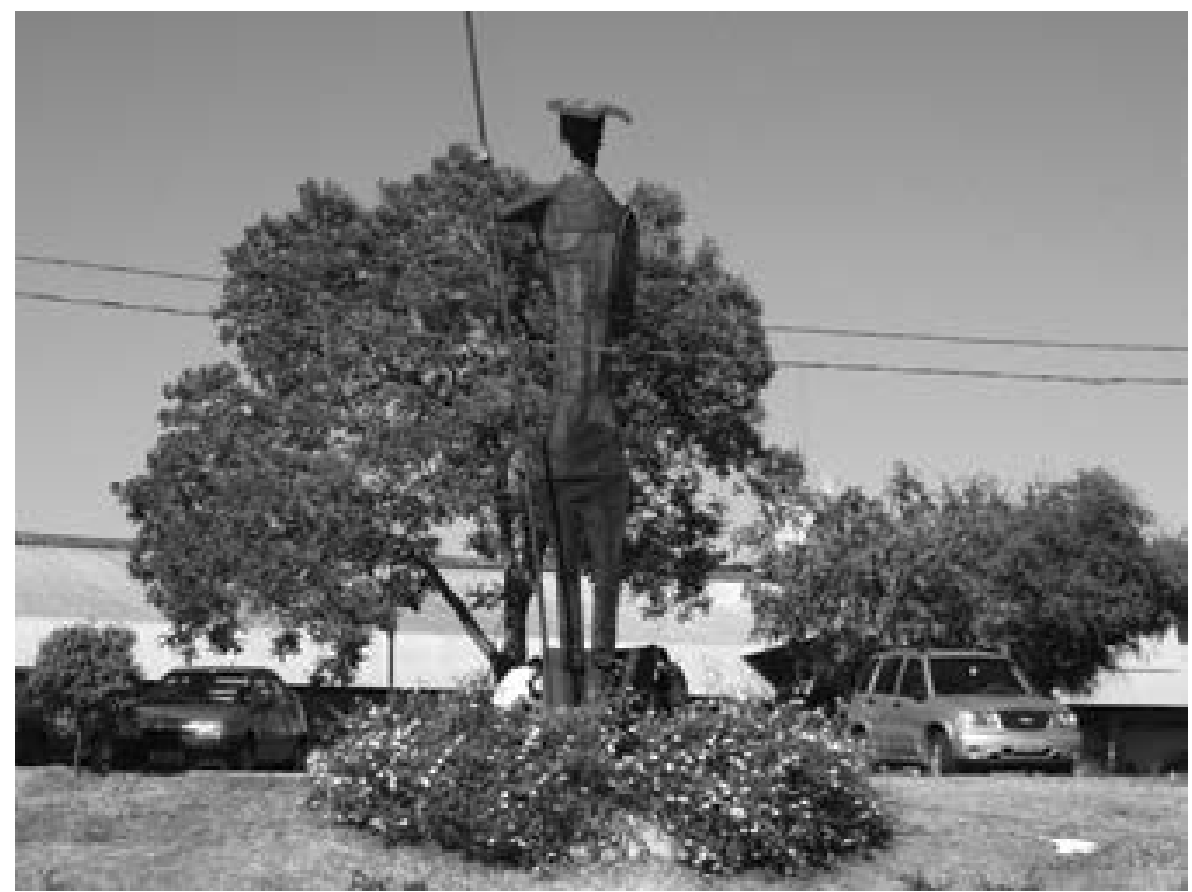

Figura 02: Circuitos globalizadores: o local e o personagem

Fonte: Soares (2011)

\section{CONSIDERAÇÕES}

Um tema recorrente para temática da cultura em tempos de globalização é, sem dúvida, a questão do hibridismo cultural. Este serve a reflexão quanto às intersecções que existem nas artes, na literatura e nas produções em geral, e no entender de como se efetiva estes processos e como ocorrem as produções culturais na atualidade. Constatar que conceitos antigos aplicam-se em nossos dias ou que já não se equivalem é ponto de partida para reafirmar que a cultura é criada em relação aos indivíduos, dentro de suas idéias, seus valores, seus modos de viver.

Em uma era de intenso fluxo social, de intercâmbios e trocas, a individualidade dos atores sociais é influenciada por múltiplos processos culturais, os quais refletem em suas produções também características múltiplas. Compreender tais processos é compreender a ação humana em suas diversas dimensões.

A obra de Cervantes, mais especificadamente seu personagem principal, retratado em esculturas é uma mostra peculiar de que as mesclas são também 
"fusões artísticas, literárias e comunicacionais" (CANCLINI, 2008, p. XVIII). Seus expoentes podem ser observados no regional do Rio Grande do Sul, demonstrando o quanto as tendências globais salientam as especificidades locais.

\section{REFERÊNCIAS}

ADORNO, Theodor W. A Indústria Cultural in COHN, Gabriel. Comunicação e indústria cultural. São Paulo: Editora Nacional, 1971.

BURKE, Peter. Hibridismo Cultural. São Leopoldo: Ed. Unisinos, 2003.

CANCLINI, Nestor Garcia. A globalização imaginada. São Paulo: Iluminuras, 2007. . As culturas populares no capitalismo. São Paulo: Editora Brasiliense, 1983. . Consumidores e Cidadãos. Rio de Janeiro, Editora UFRJ: 2003. . Culturas Híbridas: Estratégias para entrar e sair da Modernidade. São Paulo: Ed.USP, 2008. CARY, Nelson; GROSSBERG, Lawrence e TREICHLER, Paulo A. Cultural Studies. New York: Routlegde, 1992.

CUCHE, Denys. A noção de Cultura nas Ciências Sociais. São Paulo: EDUSC, 1999.

HOLLANDA, Heloísa Buarque de. Estudos Culturais na Academia in Seminário Trocas Culturais na Era da Globalização. Rio de Janeiro, 1996 - capturado do site < http://www.ufrj.br/ pacc >. Disponibilizado em 18 de agosto de 2001.

MARTIN-BARBERO, Jesús. Dos meios às mediações: comunicação, cultura e hegemonia. Rio de Janeiro: Editora UFRJ, 2006.

KELLNER, Douglas. A cultura da mídia. São Paulo: EDUSC, 2002.

STRELOW, Aline. Pampa e cultura: O hibridismo cultural no Rio Grande do Sul. Revista Elementa. Comunicação e Cultura. Sorocaba, v.1, n.2, jul/dez. 2009.

THOMPSOM, John B. Ideologia e cultura moderna. Teoria social e crítica na era dos meios de comunicação de massa. Petrópolis: Vozes, 1995.

VILA NOVA, Sebastião. Introdução à sociologia. São Paulo: Atlas, 2004.

WARNIER, Jean-Pierre. A mundialização da Cultura. Bauru SP: EDUSC, 2000.

WILLIAMS, Raymond. Cultura. Rio de Janeiro: Paz e Terra, 1992.

WOLF, Mauro. Teorias da comunicação. Trad. Maria Jorge Vilar de Figueiredo. Lisboa: Presença, 1995. 


\section{Karen Greco Soares}

Graduanda em Comunicação Social - Relações Públicas com Ênfase em Produção Cultural da Universidade Federal do Pampa. Tem experiência na área de Comunicação, com ênfase em Relações Públicas, Sociologia da Comunicação e Cultura, atuando principalmente nos seguintes temas: consumo informativo, mídia e juventude, cultura; hibridismo cultural; arte; comunicação; rio grande do sul; mídia; cultura regional.

\section{Tiago Costa Martins}

Mestre em Desenvolvimento Regional pela Universidade de Santa Cruz do Sul (2009), bacharel em Comunicação Social, hab. Relações Públicas, pela Universidade Federal de Santa Maria (2002). Tem experiência técnica profissional na área de Comunicação governamental em âmbito local e regional. Membro da equipe de pesquisadores do projeto Práticas Socioculturais Fronteiriças na Mídia Online (UFRGS). Doutorando em Desenvolvimento Regional pela UNISC. Atualmente é professor Assistente do Curso de Relações Públicas da Universidade Federal do Pampa - São Borja. 